\title{
Estudo etnobotânico de Mauritia flexuosa L. f. (Arecaceae) em comunidades ribeirinhas do Município de Abaetetuba, Pará, Brasil'
}

\author{
Ronize da Silva SANTOS², Márlia COELHO-FERREIRA ${ }^{3}$
}

\begin{abstract}
RESUMO
Dada a relevância cultural e econômica do miriti (Mauritia flexuosa L. f.) em Abaetetuba-PA, principalmente na confecção de produtos artesanais, este trabalho teve como objetivo registrar informaçóes a respeito do uso dado à folha desta palmeira pelas comunidades ribeirinhas de Sirituba, Tauerá, Acaraqui e Arapapuzinho, do referido município. Estas foram selecionadas durante oficina de mapeamento participativo, realizado pelo "Projeto Miriti", executado pelo Centro Internacional de Pesquisa Florestal (CIFOR). Os informantes $(\mathrm{n}=45)$ foram amostrados de forma probabilística, através da amostra por conglomerados. Para a coleta de dados aplicaram-se as técnicas de entrevista semi-estruturada, listagem livre, indução não-específica e observação participante. Foi calculado o valor de diversidade do informante (IDs) e o índice de Sørensen para análise de similaridade dos usos entre as comunidades. Vinte e seis produtos confeccionados foram identificados, 15 dos quais referenciados como "artesanato popular local". "Paneiro", "rasa", "tipiti”, "abano", "matapi” e "peneira" foram considerados os utensílios culturalmente mais importantes. O valor de diversidade do informante (IDs) entre os entrevistados das quatro comunidades com relação à quantidade de produtos utilizados apresentou-se significativamente homogêneo. Os maiores índices de similaridade constatados foram entre as comunidades de Sirituba e Acaraqui e os menores entre Arapapuzinho e Acaraqui. O miriti possui expressiva importância para os ribeirinhos de Abaetetuba em muitos aspectos. O número de produtos identificados foi alto, e embora nem todos os objetos sejam utilizados no dia-a-dia eles possuem relevância econômica, uma vez que sua comercialização contribui para a renda dos moradores.
\end{abstract}

PALAVRAS-CHAVE: Ribeirinhos amazônicos, Miriti, Artesanato.

\section{The ethnobotanical study of Mauritia flexuosa L. f. (Arecaceae) in riverine communities of Abaetetuba county, Pará state, Brazil}

\section{ABSTRACT}

The miriti (Mauritia flexuosa L.f.) is of great cultural and economic importance in the county of Abaetetuba, Pará state, principally to make artisanal crafts and products. Given the significance of this species in Abaetetuba the purpose of this study was to gather information on the use of these fronds. A representative sample from four Abaetetuba communities, Sirituba, Tauerá, Acaraqui and Arapapuzinho $(\mathrm{n}=45)$, was selected to participate in a local mapping workshop conducted by the Miriti Project, executed by CIFOR (Centro Internacional de Pesquisa Florestal). Research was conducted through semi-structured interviews, free listing, non-specific frame elicitation and participant observation. An index value for informant diversity (IDs) was calculated and the Sørensen index was used to analyze similarity between communities. A total of 26 items were crafted from palm fronds of which 15 were cited as being popular artisanal products. "Paneiro", "rasa", "tipiti", "abano", "matapi" e "peneira" were considered the most culturally important. The IDs between informants in the four communities for the quantity of important products showed a high uniformity. The highest index of similarity was encountered between the communities of Sirituba and Acaraqui and the lowest was encountered between Arapapuzinho and Acaraqui. All told, miriti is of high value to the riverine dwellers of Abaetetuba. The number of craftwork items was high and although many of these products are not used on a daily basis, they are of distinct economic importance, as the marketing of these products contributes to the earnings of local residents.

KEYWORDS: Riverine Amazonians, Miriti, Craftwork

\footnotetext{
1 Parte da dissertação de mestrado da primeira autora. Bolsista BECA/IEB - Projeto Miriti/ CIFOR

2 Museu Paraense Emílio Goeldi. ronizess@yahoo.com.br

${ }^{3}$ Museu Paraense Emílio Goeldi. mcoelho@museu-goeldi.br
} 


\section{INTRODUÇÃO}

Vários trabalhos etnobiológicos vêm sendo desenvolvidos sobre o aproveitamento dos recursos naturais pelos povos de diferentes regióes e etnias (Almeida e Albuquerque 2002), dentre estes, o campo de estudo mais avançado, principalmente na Amazônia, é o da etnobotânica (Prance 1972; Begossi 1996; Campos e Ehringhaus 2003).

Informaçôes obtidas através da etnobotânica podem esclarecer o nível de dependência de uma comunidade em relação aos recursos vegetais locais, além de dar subsídio ao conhecimento sobre as consequências de determinados tipos de exploração desses recursos (Philips 1996).

Estomba et al. (2006) relatam que a preferência por determinada fonte de recurso pode refletir os aspectos sócioculturais da comunidade, e as características dessa preferência, segundo Amorozo (2002), também podem ser observadas por algumas modificaçôes antrópicas ocorrentes no ambiente nos quais essas populaçóes vivem.

As populaçôes tradicionais que vivem nas florestas de várzea do estuário amazônico, regionalmente denominadas ribeirinhos, são detentoras de saberes associados ao uso de espécies encontradas predominantemente nesses ambientes. Dentre essas, encontram-se várias palmeiras, exploradas pelas populaçôes locais pelo fato de apresentarem múltiplos usos que satisfazem suas necessidades de subsistência. Entre elas destacase o miriti (Mauritia flexuosa L.f), uma palmeira que marca a paisagem do estuário pela exuberância e pelo seu grande porte, podendo chegar até $30 \mathrm{~m}$ de altura, se sobressaindo na vegetação, formando o dossel da floresta. Pode ser dióica ou polígamo- dióica, sendo encontrada naturalmente em várias formaçóes vegetais, preferindo áreas alagadas, onde forma extensos agrupamentos denominados miritizais ou buritizais. Está distribuída em toda a regiáo amazônica e, no Brasil, é particularmente frequente nas baixadas úmidas de áreas de cerrado do país (Henderson 1995; Cavalcante 1996; Nascimento 2010).

Essa palmeira é utilizada de diversas formas pelos ribeirinhos. O fruto é uma importante fonte de alimentação, os troncos são usados como pontes $\mathrm{e}$ as folhas destinadas à cobertura de casas, enquanto suas fibras servem para a confecçấo de utensílios diversificados que auxiliam nas atividades do cotidiano, bem como na confecção de artesanato característico dessas comunidades (Anderson 1977; Valente 2002).

No Município de Abaetetuba-PA é comum a prática do extrativismo das folhas do miriti para a confecção de variados utensílios artesanais, empregados pelas populaçôes locais tanto para subsistência como comercialização. Assim, levando em consideração a importância que essa palmeira representa para as comunidades mencionadas, foi realizado um estudo neste município, com objetivo de registrar informaçôes a respeito do uso desta palmeira, dando ênfase ao aproveitamento de suas folhas, sobretudo no artesanato.

\section{MATERIAL E MÉTODOS}

\section{Localização e caracterização da área de estudo}

O Município de Abaetetuba, pertencente à mesorregião do nordeste paraense, situa-se nas coordenadas geográficas de 01043'24"de latitude Sul e 48 52'54" de longitude Oeste (IBGE 2007) (Figura 1). Possui uma populaçáo de 139.819 habitantes, tendo como principais fontes de renda o comércio, além da agricultura, pecuária e extrativismo, principalmente de madeira, fibras, palmito e frutos de açaí e miriti (IBGE 2007). A população ribeirinha de 35.000 habitantes, denominados de "moradores das ilhas" ou "ribeirinhos", está localizada, sobretudo nas ilhas (Hiraoka e Rodrigues 1997).

Predominam no município o latossolo amarelo distrófico de textura média, associado ao podzol hidromórfico e solos concrecionários lateríticos indiscriminados distróficos, textura indiscriminada, em relevo plano. O clima é super úmido, com altas temperaturas, inexpressiva altitude térmica e precipitaçôes ambulantes (Seplan 2005). Possui 72 ilhas, situadas na confluência do rio Tocantins com o rio Pará, no estuário do rio Amazonas. Nessa área predominam as várzeas de marés, cuja topografia náo é uniforme, apresentando relevo bastante variado. Geralmente o terreno é mais alto ao longo dos rios e mais baixo à medida que se distância das margens. As áreas de melhor drenagem são chamadas de várzea alta enquanto que terrenos pantanosos são denominados de várzea baixa. Embora a várzea da regiáo náo ultrapasse $4 \mathrm{~km}$ em largura, ela comporta a maior densidade demográfica rural da regiáo (Hiraoka e Rodrigues 1997).

As florestas de várzea apresentam vegetação característica, com espécies ombrófilas latifoliadas, intercaladas com palmeiras, dentre as quais despontam o açaí (Euterpe oleracea Mart.) e o miriti (Almeida et al. 2004).

Um dos principais eventos locais é a realização do Miriti Fest, onde vários artesãos expóem seus brinquedos produzidos a partir dessa palmeira, para apreciação e venda. Em 2006, o evento recebeu cerca de 40 mil pessoas, e a exposição contou com mais de 15 mil peças, entre elas as tradicionais cobras, barquinhos e dançarinos, e os modernos móbiles e embalagens (Cifor 2008).

\section{Seleção das comunidades e dos informantes}

Quatro comunidades ribeirinhas - Tauerá, Acaraqui, Sirituba e Arapapuzinho, esta última, de origem quilombolaforam selecionadas devido à expressiva utilização de 


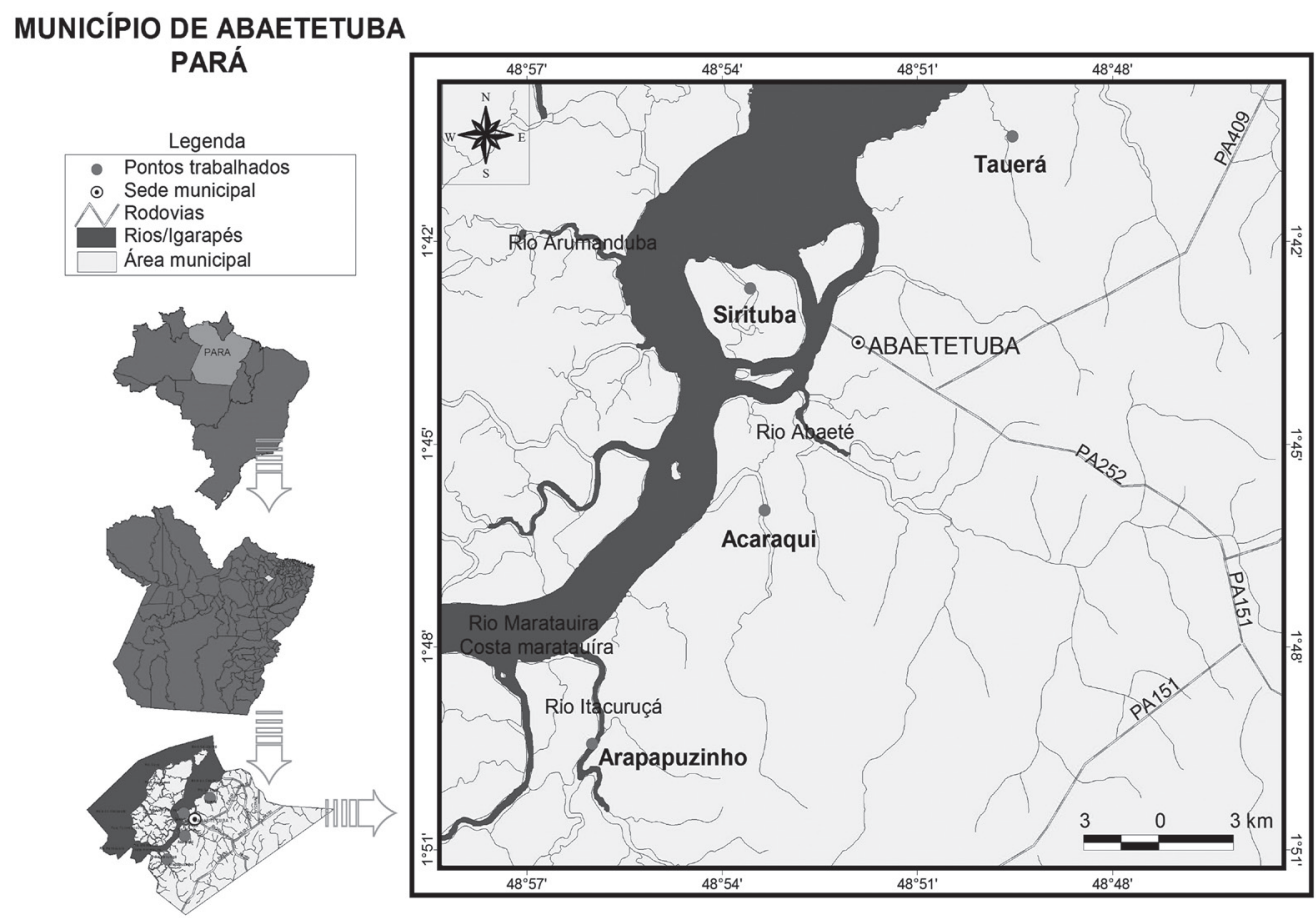

Figura 1 - Localização do Município de Abaetetuba-PA e das comunidades estudadas.

miriti, sobretudo para o artesanato. Foram indicadas pelos comerciantes da feira livre da sede do município e confirmadas durante oficina de mapeamento participativo, realizada pelo "Projeto Miriti", coordenado pelo Centro Internacional de Pesquisa Florestal - CIFOR, o qual desenvolveu estudos sobre aspectos ecológicos, econômicos e histórico-culturais desta espécie, tendo em vista melhorias no seu uso e conservação no âmbito deste município.

A amostra populacional foi de 45 informantes, dos gêneros masculino (27\%) e feminino ( $73 \%$ ). A idade variou entre 21 e 87 anos. A faixa etária de 21 a 30 anos apresentou o maior número de informantes $(\mathrm{n}=14)$, onde as mulheres representaram aproximadamente $86 \%$ da amostra. Com exceção da faixa etária de 81 a 90 anos, o gênero feminino foi também superior ou igual ao masculino nas demais.

Os informantes foram escolhidos por amostragem probabilística, por meio da amostra por conglomerados (Albuquerque et al. 2010). Em cada comunidade selecionada foi escolhido o conglomerado com o maior número de residências, sendo que todas estas foram consideradas. Somente pessoas adultas foram entrevistadas, ou seja, o homem ou a mulher e quando possível, o casal. Este último caso se concretizava quando, no ato da entrevista, o primeiro entrevistado citava seu companheiro como sendo a pessoa que detinha maior conhecimento sobre a palmeira.

\section{Coleta e análise de dados}

As informaçôes foram coletadas ao longo de cinco viagens, realizadas no período de setembro a novembro de 2008 . As técnicas de coleta de dados empregadas - observação participante, entrevistas semi-estruturadas, listagem livre e indução não específica - foram baseadas em Albuquerque $e t$ al. (2010).

A observaçáo participante, utilizada durante todo o trabalho de campo, propiciou informaçóes relacionadas ao estilo de vida dos moradores, como características das casas, tipos de transportes e outras informações dificilmente capturadas em forma de entrevistas.

Entrevistas semi-estruturadas, visando à obtenção de informaçóes sobre os entrevistados (idade, sexo, escolaridade e tempo de residência na localidade e atividades econômicas desenvolvidas), além de aspectos etnobotânicos (origem do conhecimento, tipos de produtos confeccionados com a folha do miriti, parte da folha utilizada, objetos que deixaram de ser utilizados) foram conduzidas individualmente, gravadas e anotadas.

A listagem livre parte do princípio que os produtos primeiramente citados, e com maior frequência de citação, são os que têm maior importância cultural. Esta técnica foi utilizada para a identificação dos produtos artesanais culturalmente mais relevantes para os ribeirinhos amostrados. 
Foi aplicada ainda a técnica de indução não específica, sugerida por Brewer (2002) apud Albuquerque et al. (2010) para subsidiar a anterior, e consistiu em questionar o informante logo após o mesmo declarar não recordar de mais elementos, estimulando a lembrança.

Para este trabalho o termo produto refere-se às diversas formas de uso material da folha, incluindo desde utensílios como as cestarias (abano, cestos, paneiro, etc.) até paredes e cobertura de casas. A categorização de uso destes produtos está baseada em Ribeiro (1985) e Jardim e Stewart (1994).

Foi utilizado o índice de similaridade Sørensen, o qual vem sendo aplicado na etnobotânica para comparar as espécies úteis entre áreas, independente de ter havido amostragem de vegetação (Albuquerque et al. 2010). Neste estudo, houve uma adaptação do mesmo para comparar a similaridade de produtos elaborados a partir da folha de miriti, entre as comunidades estudadas, visando estabelecer as características peculiares de cada uma e suas semelhanças. Para isto foi utilizada a seguinte fórmula:

$$
\text { Ss }=2 \mathrm{a} /(2 \mathrm{a}+\mathrm{b}+\mathrm{c})
$$

Onde Ss indica o coeficiente de similaridade de Sørensen; a, o número de usos comuns as comunidades 1 e 2 que estáo sendo comparadas; b, número de usos que ocorre apenas na comunidade 2; c, número de usos que ocorre apenas na comunidade 1 .

Também foi analisado o valor de diversidade do informante (IDs), proposto por Byg e Balslev (2001), para estudos com palmeiras, e que mede quantos informantes usam a espécie e, como seu uso está distribuído entre eles. Este índice é obtido através da seguinte fórmula:

$$
\mathrm{IDs}=1 / \sum \mathrm{Pi}^{2}
$$

Onde PI é a contribuição do informante i para o conjunto do conhecimento total da espécie s (número de registros de uso da espécie s pelo informante i, dividido pelo número total de registro de uso da espécie s).

\section{RESULTADOS E DISCUSSÃO}

\section{As comunidades e os ribeirinhos}

As residências estão normalmente situadas às margens dos rios, tidas como áreas bastante alteradas pelas intensas açôes antrópicas. As casas, suspensas e protegidas dos movimentos das marés, em geral são feitas de madeira e cobertas por telhas de barro ou folhas de palmeiras, regionalmente denominadas "palhas". Algumas moradias apresentam um pequeno trapiche coberto de palha, que serve para embarque e desembarque de mercadorias e pessoas, caracterizando o típico cenário das residências do estuário.

Segundo os moradores, as comunidades ribeirinhas do Município de Abaetetuba frequentemente recebem o nome do rio à margem do qual se estabelecem, característica peculiare a muitas comunidades de várzeas do estuário amazônico. As atividades econômicas se baseiam na agricultura e no extrativismo de produtos florestais, complementados pela pesca, principalmente do camarão, além de pequenas criaçôes de animais (galinhas, patos e porcos) para o consumo doméstico. Estas práticas sáo comumente relatadas em estudos envolvendo populaçóes ribeirinhas na região Amazônica (Anderson et al. 1985; (Hiraoka e Rodrigues 1997).

De um total de 45 informantes, onze mencionaram como principal atividade a confecção de cestarias, seis são artesãos de brinquedos, sete agricultores, dois professores, quatro extratores de açaí e quinze são donas de casa, das quais seis são também artesãs de cestarias.

A confecção de cestarias é uma atividade tradicional e muito fluente entre os moradores, praticada tanto pelos mais idosos como pelos mais jovens. Vale ressaltar, que as cestarias incluem todos os objetos confeccionados a partir da fibra da folha trançada. Geralmente são as mulheres que se dedicam à confecçáo destes produtos, sobretudo aqueles de uso doméstico, enquanto os homens atuam na confecção de produtos empregados nas atividades econômicas (pesca, agricultura e extrativismo). Sousa (2009) identificou divisão de tarefas semelhante entre homens e mulheres na Reserva de Desenvolvimento Sustentável do Amanã, não somente na confecção de determinados objetos, como também na coleta da matéria-prima. Alguns autores relataram que especialmente no uso de espécies fibrosas voltados para a produção de artefatos, as mulheres sempre aparecem compondo parte da cadeia seja na coleta, confecção ou na comercialização (Gallegos e Burbano 2004; Leoni e Marques 2008; Sousa 2009).

Apesar da maioria dos entrevistados (96\%) possuírem açaizais em suas propriedades, apenas quatro identificaram-se como "extratores" de frutos dessa palmeira, por se dedicarem mais intensamente e durante a maior parte do ano a essa atividade. $\mathrm{O}$ açaí é um dos produtos mais importantes para os povos ribeirinhos do estuário amazônico, não somente por fazer parte do seu hábito alimentar, mas principalmente por garantir fonte de renda através de sua comercialização. Para Jardim e Cunha (1998), a importância dessa palmeira acaba influenciando na estrutura organizacional das comunidades, uma vez que o extrativismo dos frutos reflete diretamente na condiçáo sócio-econômica e alimentar.

\section{Principais usos do miriti}

O miriti apresenta expressiva importância para as comunidades estudadas, uma vez que possui todas as suas partes utilizáveis. Os frutos são comercializados por $60 \%$ dos informantes, sendo usados na alimentação, podendo ser consumidos in natura, sob a forma de mingaus, vinhos, 
bolos, picolés, entre outros. A relevância destes e as formas sob as quais são aproveitados são atestadas por vários trabalhos realizados na regiấo Amazônica, como demonstrado por Magalhães e Coelho-Ferreira (2007), na comunidade Ererê Município de Monte Alegre, Pará e por Manzi e Coomes (2009), na comunidade de Roca Fuerte no Peru. Mejía (1992) comenta ainda que o fruto do miriti é um dos mais comercializados nos mercados de Iquitos no Peru.

Apenas 16\% dos entrevistados afirmam utilizar o tronco, ainda que se tenha observado que a maioria dos ribeirinhos o utiliza em suas residências, como pontes ou portos. Além disso, os troncos de miriti servem como jangadas, auxiliando no transporte da madeira das áreas de extração para as serrarias.
As folhas são empregadas na confecção de variados produtos artesanais, sendo que todos os entrevistados citaram algum tipo de produto e $67 \%$ também fazem a venda destes, embora de maneira bem modesta, geralmente por encomenda por parte de outros moradores. Assim como os troncos, as folhas são amplamente usadas na Amazônia, a exemplo dos registros feitos para a Ilha do Combu, Município do Acará, Pará (Jardim e Cunha 1998) e Novo Airão, Amazonas (Jardim e Stewart 1994).

\section{Usos das folhas}

Nas quatro comunidades estudadas foram identificados 26 produtos confeccionados artesanalmente, cujos usos estão listados na Tabela 1. Entre estes, doze merecem destaque por

Tabela 1 - Utilidades da folha da Mauritia flexuosa L. f. citadas por 45 moradores ribeirinhos das quatro comunidades estudadas do Município de Abaetetuba, Pará, Brasil (dom= doméstico; cons $=$ construção e ae $=$ atividade econômica).

\begin{tabular}{|c|c|c|c|c|}
\hline Produto & $\mathrm{N}^{0}$ de citações & Parte da folha utilizada & Utilidade & Categoria de uso \\
\hline Paneiro & 42 & Fibra & $\begin{array}{l}\text { Carregar frutas e algumas aves para } \\
\text { serem vendidos na feira }\end{array}$ & dom/ae \\
\hline Rasa & 28 & Fibra & Carregamento do açaí e miriti & dom/ae \\
\hline Envira & 24 & Fibra da folha nova/grelo & Amarrações em geral & dom/cons/ae \\
\hline Matapi & 22 & Fibra & Pescar camarão & dom/ae \\
\hline Tipiti & 20 & Fibra & Espremer a mandioca & dom/ae \\
\hline Brinquedo & 19 & Medula & Ornamental & ae \\
\hline Abano & 17 & Fibra & Fazer fogo & dom \\
\hline Corda & 14 & Fibra da folha nova/grelo & Para amarrar rede e outros & dom/ae \\
\hline Bóia para matapí & 11 & Medula & Segura o matapi para não afundar & ae \\
\hline Peneira & 10 & Fibra & Coar o açaí, miriti e a mandioca & dom/ ae \\
\hline Paredes e janelas de casas & 10 & Medula & Acabamento de construção & cons \\
\hline Cesto & 8 & Fibra & Carregar mercadorias & dom \\
\hline Gaiola & 7 & Fibra & Aprisionar pássaros & dom \\
\hline Panacarica & 7 & Fibra & Cobrir roupas & \\
\hline Mão de juda & 5 & Fibra & Suporte & dom \\
\hline Aricá & 5 & Fibra & Pescar camarão & ae \\
\hline Rede & 6 & Fibra da folha nova/grelo & Para uso humano/descanso & dom \\
\hline Tupé & 5 & Fibra/ tala & Usado para secar camarão & dom \\
\hline Peconha & 5 & Fibra da folha nova/grelo & Subir no açaizeiro & ae \\
\hline Maqueira & 4 & Fibra da folha nova/grelo & Tipo de rede & dom \\
\hline Rabo de foguete & 3 & Fibra & foguete & dom \\
\hline Cobertura de casas & 2 & Toda folha & Cobrir casas e barracões & cons \\
\hline Esteira & 2 & Fibra & Forrar o chão para a dormida & dom \\
\hline Aturá & 1 & Fibra & Transportar mandioca, milho, arroz & ae \\
\hline Paiol & 1 & Fibra & Carregar pão & dom \\
\hline Rolha para garrafa & 1 & Medula & Tampar as garrafas e vidros. & dom \\
\hline Total & 279 & & & \\
\hline
\end{tabular}


terem recebido o maior número de citação $(\geq 10)$, são eles: "paneiro", "rasa”, "matapi”, "brinquedo", “tipiti”, "abano”, "corda”, "peneira”, envira, "bóia para matapi”, paredes e janelas de casas.

Valente (2002), relatou que paneiro, peneira, tipiti e abano são objetos utilizados por moradores da comunidade de Caxiuanã, Melgaço-PA, onde sua comercialização, realizada em pequena escala, aumenta a renda familiar. A propósito, Vilhena-Potiguar et al. (1987), identificaram que além de miriti, a jacitara é outra palmeira empregada na confecção desses mesmos utensílios. Assim como, esteira e abano foram um dos objetos mais citados no estudo feito por Rufino et al. (2008) com palmeiras no Nordeste brasileiro.

A envira teve número de citação expressivo, devido estar associada a diversas formas de uso, como na amarração de feixes de cana, amarraçóes de "puqueca" (um tipo isca preparada com a polpa do miriti, utilizada para a pesca do camarão), além de servirem para amarrar as palhas nas coberturas de casas. Entre estes, a amarração de "puqueca" foi a mais representativa com 17 citaçóes, o que se explica pelo fato de estar associada à pesca do camarão, uma das atividades mais comuns e relevantes na região.

Além dos usos mencionados acima, a envira pode ser tecida para a confecção de redes e cordas; esta última, usada nas amarraçóes mais grosseiras. A diversidade de produtos bem como a especificidade de uso das fibras, no caso da envira, já tinham sido abordadas em outros estudos (Oliveira et al. 1991; Oliveira et al. 2006).

Objetos como "aturá", "paiol”, "maqueira”, "panacarica”, "aricá", "tupé” e "mão-de-juda” (Figura 2) não são atualmente tão utilizados quanto no passado e estão sendo substituídos por produtos mais modernos como sacolas plásticas e sacos de papel. Foi relatado também que alguns jovens das comunidades só conhecem esses produtos através de comentários dos mais antigos ou como decoração em certos ambientes, a exemplo de bares locais. Entre esses utensílios, o "aturá" foi mencionado por Ribeiro (1985), como produto confeccionado a partir do cipó ambé, usado pelos índios Makú, Yanomami e pelos indígenas do alto rio Negro.

Dos produtos citados, o cesto é um dos poucos que apresenta várias formas geométricas. Dependendo da finalidade de uso, pode ser comprido, pequeno, redondo, com tampa ou sem tampa, com alça ou sem alça. Essas formas diversificadas foram descritas por Ribeiro (1985), em seu estudo com traçados confeccionados por tribos indígenas do Brasil.

Foi constatado que a folha de miriti é pouco utilizada para fazer cobertura de casas, devido a sua forma. O uso das palhas de Manicaria saccifera Gaertn. (bussú) é mais frequente, por possibilitar um perfeito acabamento, vedando a entrada de
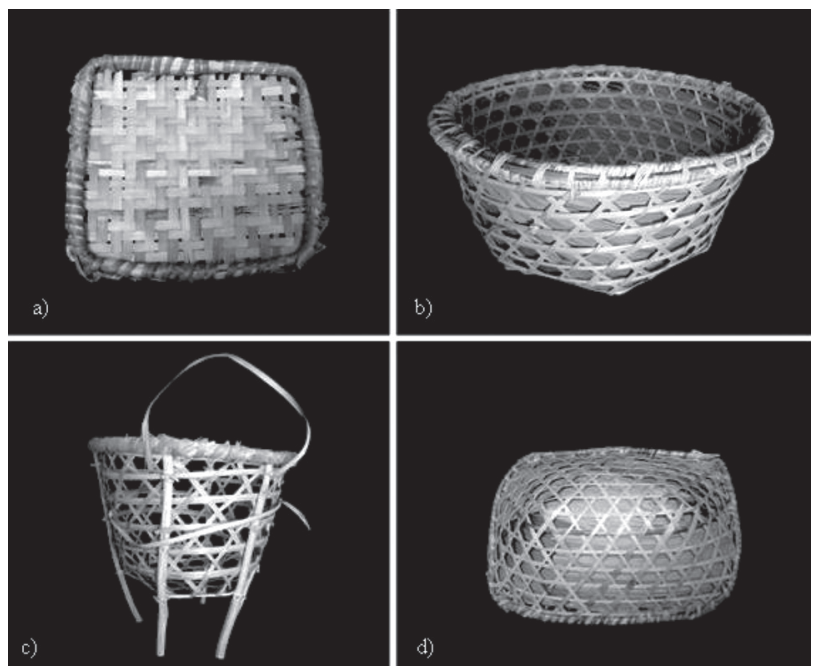

Figura 2 - Utensílios produzidos com as folhas de Mauritia flexuosa L. f. substituídos por produtos industrializados nas comunidades estudadas no Município de Abaetetuba, Pará, Brasil. a) tupé; b) paiol; c) aturá; d) panacarica.

respingo de água, o que não ocorre com a folha do miriti. De fato, esta espécie não parece ser apropriada para o uso em questão, conforme relatado em outros estudos. Além da utilização de Manicaria saccifera Gaertn. constatada em Caxiuaná, Município de Melgaço-PA. (Valente 2002; Oliveira et al. 2006) empregam Geonoma sp. (ubim) e Scheelea rostrata (Oerst.) Burret (urucuri) (Jardim e Cunha 1998); Mauritiella sp. (caranã), Bactris sp. (marajá), Astrocaryum murumuru Mart. (murumuru) e Oenocarpus bataua Mart. (patauá) (Jardim e Stewart 1994).

A construção de paredes de casas com as folhas é comum nessas comunidades, e também no Nordeste brasileiro, conforme registrado por Rufino et al. (2008) em seu estudo com as palmeiras ouricuri (Syagrus coronata) e babaçu (Orbignya phalerata), no Estado de Pernambuco. Na comunidade de Caxiuaná, Município de Melgaço-PA, todavia, os troncos (estipe), são a parte do miriti preferida para esta finalidade (Almeida e Silva 1997).

Dos 26 produtos identificados, 18 são de uso doméstico, entre os quais 11 são de uso exclusivo nesta categoria. Três destes produtos estáo voltados para a construção de casas, 12 são de uso nas atividades econômicas como na pesca do camarão, na extração de açaí, e agricultura. Entre estes, quatro são utilizados exclusivamente na atividade econômica. E sete são utilizados em ambos os contextos.

As categorias de usos mencionadas acima foram relacionadas por Ribeiro (1985), no qual, cesto, esteira, abano e corda foram classificados como sendo de uso doméstico e tipiti, matapi e peneira empregados nas atividades econômicas. Dependendo da região e das suas principais atividades 
econômicas, tais objetos podem desempenhar diferentes funçôes ou ser classificados em diferentes categorias como nos casos do aturá e da gaiola mencionados na categoria transporte no referido estudo e da esteira, citada por Ribeiro et al. (2004) para a secagem de sementes de cacau no Município de Cametá-PA.

\section{Importância cultural dos produtos feitos das folhas}

Entre os 26 produtos identificados, 15 foram mencionados como objetos do artesanato popular, sendo eles: paneiro, rasa, tipiti, abano, matapi, peneira, brinquedo, cesto, panacarica, mão-de-juda, aricá, tupé, maqueira, esteira e paiol. Os seis primeiros foram considerados culturalmente mais importantes por estarem entre as cinco primeiras citaçóes de cada informante.

A confecção de brinquedos, ao contrário das cestarias, não é prerrogativa dos ribeirinhos; sua produção, voltada para o mercado, é realizada pelas Associaçóes existentes no centro urbano. $\mathrm{O}$ aumento da popularidade e venda destes objetos reflete no dia-a-dia dos moradores; desta maneira, mesmo não fazendo parte de suas atividades cotidianas, são freqüentemente referenciados por eles. Muitos são os produtos que constituem os brinquedos de miriti, podendo ter diversas
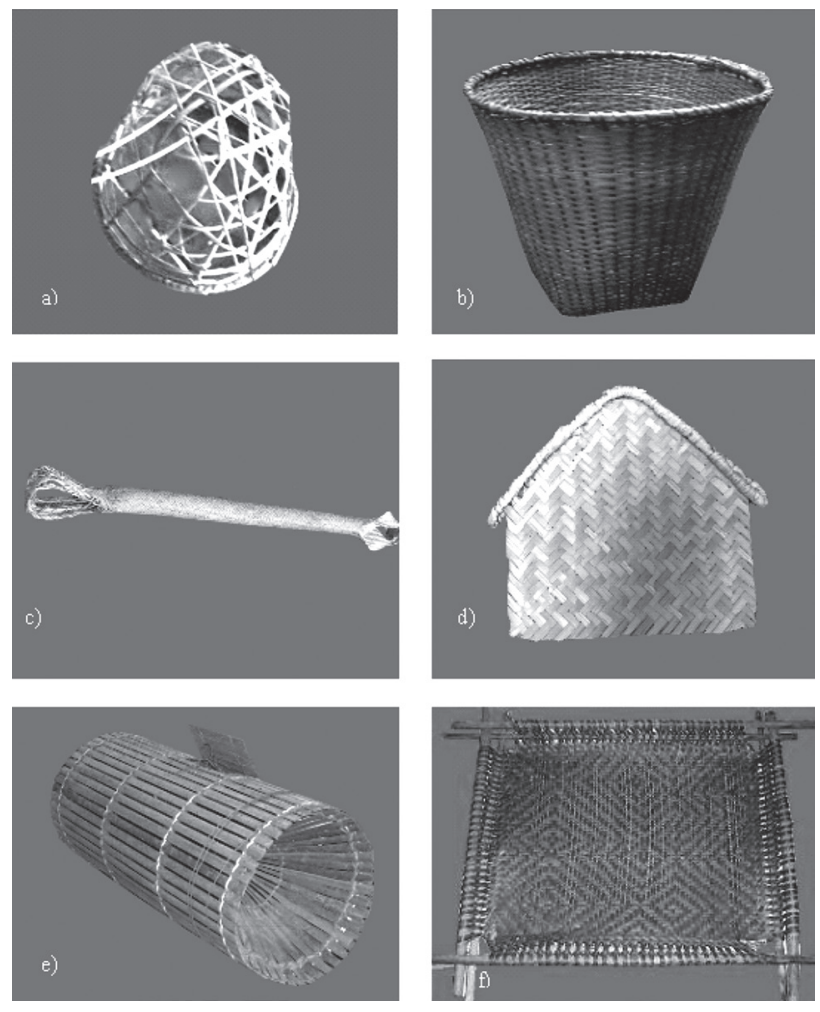

Figura 3 - Utensílios produzidos a partir de Mauritia flexuosa L. f., culturalmente mais importantes, nas comunidades estudadas do Município de Abaetetuba, Pará, Brasil. a) paneiro; b) rasa; c) tipiti; d) abano; e) matapi; f) peneira. formas e tamanhos. Geralmente representam a fauna, a flora e aspectos do cotidiano local. O uso dos brinquedos e sua importância cultural na regiâo Amazônica são apreendidos nos estudos de Cavalcante (1996); Cymerys et al. (2005), que ressaltam a relaçáo destes com a Festividade do Círio de Nossa Senhora de Nazaré na cidade de Belém-PA, quando esses produtos, confeccionados ao longo do ano são vendidos.

A importância do paneiro como o produto mais citado deve-se não somente à sua utilidade, mas por estar entre os produtos cesteiros que mantêm uma comercialização expressiva. Há de se considerar que outras comunidades do município vivem basicamente desta atividade, o que acaba repercutindo e refletindo na vida de todos os moradores da região.

A relevância do matapi, no entanto, se baseia no fato de ser um produto utilizado pelos ribeirinhos na captura do camarão, que é uma atividade exercida por todos (homens, mulheres e crianças), como foi evidenciado por Lisboa e Silva (2009) na comunidade do Aurá-PA. A venda deste artefato se intensifica durante a safra do camarão, entre os meses de maio a junho. A maioria dos entrevistados, porém, manifestou sua preferência pelo uso das fibras do jupati (Raphia taedigera (Mart.) Mart.), por conta da resistência destas. Contudo, os acabamentos, a exemplo das amarraçōes, são preferencialmente feitos com miriti. Tais procedimentos são recorrentes em outras localidades, conforme demonstrado na literatura (Jardim e Cunha 1998; Oliveira et al. 2006). O uso da rasa e da peneira está associado à coleta e ao beneficiamento dos principais produtos extrativistas locais, isto é, os frutos de açaí e do próprio miriti. Esses resultados podem ser comparados aos achados de Lisboa e Silva (2009), em estudos feitos com a palmeira. Ademais, peneira juntamente com o tipiti faz parte do processo de produçáo da farinha de mandioca, base da alimentação em toda a regiáo amazônica.

Abano é um dos objetos mais comuns no âmbito doméstico, sendo empregado no preparo do fogo. A finalidade desses utensílios também foi comentada por Ribeiro (1985).

\section{Valor de diversidade do informante (IDs) para os produtos feitos das folhas}

O IDs medido entre os entrevistados de todas as comunidades foi de 35,8 . Tendo em vista que o número total de informantes foi de 45 , a diversidade apresenta quantidades semelhantes de usos da folha entre os informantes, uma vez que, o valor encontrado está próximo do número total de informantes, demonstrando que a contribuição de cada informante para o conjunto de conhecimento sobre o uso das folhas é semelhante.

Também foi calculado o IDs para os entrevistados de cada comunidade: Sirituba e Acaraqui foram as que apresentaram menor homogeneidade entre seus informantes. A primeira 
com um IDs de 11,3 para 15 informantes e a segunda com um IDs de 8,7 para 10 entrevistados. Isso era previsto, pois nestas, alguns dos entrevistados fazem uso desta palmeira de forma mais intensa que outros, além disso, cinco entrevistados citaram de oito a 16 produtos, enquanto que os demais citavam de quatro a cinco, correspondendo a uma distribuição pouco homogênea entre eles. Cabe ressaltar que os informantes que citaram uma maior quantidade de produtos são artesãos, o que demonstra maior envolvimento destes com a espécie em questão. $\mathrm{O}$ mesmo não ocorre em Tauerá com IDs igual a 11,2 para 12 entrevistados e Arapapuzinho com o IDs de 7,2 para oito informantes, pois nessas comunidades a maioria dos entrevistados citou de três a seis usos, demonstrando uma distribuição mais homogênea com relação ao uso dos recursos oferecidos pela palmeira. Isso pode significar uma menor dependência com relação ao miriti ou pelo simples fato dos entrevistados mencionarem os produtos que são mais presentes nas atividades do cotidiano, logo há pouca variação de produtos entre os entrevistados.

\section{Similaridade de produtos feitos das folhas de Mauritia flexuosa L. f. entre as comunidades}

Os maiores índices de similaridade constatados foram entre Sirituba e Acaraqui $(0,74)$ e Tauerá e Sirituba $(0,74)$. Para as duas primeiras, presume-se que o resultado esteja associado à proximidade geográfica, o que pode ter favorecido a disseminação do conhecimento sobre o uso desta palmeira. Entre os produtos comuns às duas comunidades, estão a peçonha e o tupé, mencionados exclusivamente nessas comunidades. $\mathrm{O}$ fato das mesmas serem insulares e distantes do centro urbano as tornam mais dependentes dos recursos locais, o que poderia reforçar a similaridade constatada.

A alta similaridade entre Tauerá e Sirituba, todavia, não pode ser explicada pela proximidade geográfica. A distância de duas horas entre as duas e a proximidade de Tauerá com a cidade de Abaetetuba (20 minutos), náo serviria para explicar tal similaridade; a procedência e idade dos informantes são fatores, porém, que a explicariam. Em Tauerá, parte dos entrevistados apresentou idade acima de 40 anos e origem nas comunidades da região das ilhas.

A menor similaridade de usos do miriti foi entre Arapapuzinho e Acaraqui $(0,54)$. Ambas são ilhas localizadas a uma distância de três horas uma da outra. Além disso, Arapapuzinho é uma comunidade quilombola, cuja economia está baseada mais na agricultura do que no extrativismo, fazendo com que o uso da palmeira seja destinado principalmente à confecção de artefatos como o aturá, para transportar mandioca e milho. Diferentemente de Arapapuzinho, em Acaraqui, aonde mora alguns remanescentes quilombolas, os informantes entrevistados têm como principal atividade econômica o extrativismo, cuja demanda é por produtos como a rasa, usada na coleta de açaí.

\section{CONCLUSÕES}

Com base nos resultados encontrados se conclui que todas as comunidades utilizam o miriti para os mais variados fins. Destaque para utensílios como paneiro, rasa, tipiti e peneira que continuam desempenhando um papel significativo no cotidiano desses moradores enquanto alguns produtos são pouco utilizados nos dia de hoje ou já caíram em desuso, como maqueira e mão-de-juda.

As comunidades mais distantes da sede do município sofrem menos influência do processo de urbanização e, consequentemente, são mais dependentes dos artefatos produzidos, preservando uma maior sabedoria relacionada ao uso da folha do miriti.

Apesar de algumas comunidades apresentarem o valor de diversidade do informante (IDs) heterogêneo, essa diferença não foi significativa entre as comunidades estudadas.

Apesar da popularidade que os brinquedos possuem no município e sua expressividade econômica, estes não são considerados como produtos culturalmente importantes para os moradores ribeirinhos das comunidades estudadas.

\section{BIBLIOGRAFIA CITADA}

Albuquerque, U.P.; Lucena, R.F.P.; Alencar, N.L. 2010. Selection of survey participants, p. 21-64. In: Albuquerque, U.P.; Lucena, R.F.P; Cunha, L.V.F.C. (Eds). Methods and Techniques in Research and ethnobiologic Ethnoecology. NUPEEA, Recife (in Portuguese).

Almeida, C.F.C.B.; Albuquerque, U.P. 2002. Use and conservation of medicinal plants and animals in Pernambuco: a case study in the arid zone. Interciencia, 26: 276-285 (in Portuguese).

Almeida, S.M.; Amaral, D.D.; Silva, A.S.L. 2004. Floristic analysis and structure of tidal flooded forests in the amazonian estuary. Acta Amazonica, 34: 513-524 (in Portuguese).

Almeida, S.S.; Silva, P.J.D. 1997. As palmeiras: Palms: botanical aspects, ecological and economic, p. 235-251. In: Lisboa, P.L.B. (Eds). Caxiuanã. Museu Paraense Emílio Goeldi, Belém (in Portuguese).

Amorozo, M.C.M. 2002. Use and diversity of medicinal plants in Santo Antonio Leverger, MT, Brasil. Acta Botanica Brasilica, 16: 189-203 (in Portuguese).

Anderson, A.B. 1977. Names and uses of palms among a tribe of Indians Yanomama. Acta Amazonica, 7: 5-13 (in Portuguese).

Anderson, A.B.; Gely, A.; Strudwick, J.; Sobel, G.L.; Pinto, M.G.C. 1985. An agroforestry system in the floodplain of the Amazon estuary (Island of the Jaguars, Barcarena County, State of Pará. Acta Amazonica, 15:195-224. Suplemento (in Portuguese).

Byg, A.; Balslev, H. 2001. Diversity and use of palms in Zahamena, eastern Madagascar. Biodiversity and Conservation, 10: 951-970.

Begossi, A. 1996. Use of ecological methods in ethnobotany. Economic Botany, 50:280-289.

Campos, M. T.; Ehringhaus, C. 2003. Plant virtues are in the eyes of the beholders: a comparison of known palm uses among 
indigenous and folk communities of southwestern Amazônia. Economic Botany, 57: 324-344.

Cavalcante, P.B. 1996. Edible fruits of the Amazon. Museu Paraense Emílio Goeldi, 6a Ed. Belém. 279 pp (in Portuguese).

Cifor (Centro Internacional de pesquisa Florestal) Project Report Miriti. 2008 (in Portuguese).

Cymerys, M.; De Paula Fernandes, N.M.; Rigamonte-Azevedo, N.O.C. 2005. Buriti (Mauritia flexuosa L. f.), p. 181-187. In: Shanley, P.; Medina, G. (Eds). Fruit and Useful Plants in Amazonian Life. Centro internacional de pesquisa florestalCIFOR, Imazon, Belém (in Portuguese).

Estomba, D.; Ladio, A.; Lozada, M. 2006. Medicinal wild plant knowledge and gathering patterns in a Mapuche community from North-western Patagonia. Journal of Ethnopharmacology, 103: 109-119.

Gallegos, R.A.; Burbano, M. F. 2004. Using Straw scarf (Carludovica palmata Ruiz \& Pavón), in developing em hats three communities in the province of Manabi, Equador, p.463-481. In: Alexiades M. N; Shanley, P. (Eds.) Forest products, livelihoods and conservation: Case studies on management systems of non-timber forest products.V.3. Indonesia. (in Spanish).

Henderson, A.; Galeano, G.; Bernal, R. 1995. A field guide to the palms of the Americas. Princeton University Press, New Jersey. $498 \mathrm{pp}$.

Hiraoka, M.; Rodrigues, D.L. 1997. Pigs, Palms and Riverside in the floodplain of the Amazon Estuary, p.71-101. In: Furtado, L. G. (Eds). Amazon: development, biodiversity and social quality of life.UFPA / NUMA, Belém (in Portuguese).

Instituto Brasileiro de Geografia e Estatística - IBGE. 2007 (www. ibge.gov.br). Acesso em 07/04/2009.

Jardim, M.A.G.; Cunha, A.C.C. 1998. Uses of palm trees in a riparian community of the Amazon estuary. Boletim do Museu Paraense Emilio Goeldi, Série Botânica, 14: 69-77. (in Portuguese).

Jardim, M.A.G.; Stewart, P.J. 1994. Ethnobotanical and ecological aspects of palm trees in the City of New Airão, State of Amazonas, Brasil. Boletim do Museu Paraense Emílio Goeldi, Série Botânica, 10: 69-76 (in Portuguese).

Leoni, J.M.; Marques, T. S. 2008. Knowledge of craftsmen on the plants used in the production of artifacts, Sustainable Development Reserve, Amanã, AM. Uakari,4: 67-77 (in Portuguese).

Lisboa, P.L.B.; Silva, M.L. 2009. The management of biological resources, p. 92-173. In: Lisboa, P.L.B. (Eds). Aurá: comunidades eflorestas. Museu Paraense Emílio Goeldi, Belém (in Portuguese).

Magalhães, J.L.; Coelho-Ferreira, M. 2007. The Buriti Ererê (Monte Alegre, $\mathrm{Pa}$ ) and prospects for community management, p. 95104. In: Albuquerque, U.P.; Alves, A.G.C.; Araújo, T.A.S. (Eds). Landscapes and People: Ethnobiology, Ethnoecology and Biodiversity in Brazil. Nupeea, Recife (in Portuguese).
Manzi, M.M; Coomes, O.T. 2009. Managing Amazonian palms for community use: A case of aguaje palm (Mauritia flexuosa) in Peru. Forest Ecology and Management, 257: 510-517.

Mejía, K. 1992. Palms in Iquitos markets. Bulletin de l'Institut Français d'études Andines, 21:755-769 (in Spanish).

Nascimento, A.R.T. 2010. Richness and ethnobotany of palms in kraho indigenous territory, Tocantins, Brazil. Floresta, 40: 209-220 (in Portuguese).

Oliveira, J.; Almeida, S.S.; Vilhena- Potiguara, R.C.; Lobato, L.C.B. 1991. Plant Species producing fibers used by Amazonian communities. Boletim do Museu Paraense Emílio Goeldi, Série Botânica, 7: 393-428 (in Portuguese).

Oliveira, J.; Potiguara, R.C.V.; Lobato, L.C.B. 2006. Used vegetable fibers in the Artisanal Fisheries in the Salgado microregion, Pará Boletim do Museu Paraense Emílio Goeldi, Ciências Humanas, 1: 113-127 (in Portuguese).

Phillips, O.L. 1996. Some quantitative methods for analyzing ethnobotanical knowledge, p.171-197. In: Alexiades, M.N. (Eds). Selected guidelines for ethnobotanical research: a field manual. New York BotanicalGarden, New York.

Prance, G. T. 1972. Ethnobotanical Notes from Amazonian Brazil. Economic Botany, 26 (3): 221-237.

Ribeiro, B.G.A. 1985. Art of weaving of the Indians of Brazil: A taxonomic study. Belém, Museu Paraense Emílio Goeldi. Instituto Nacional do Folclore, Rio de Janeiro. 185 pp (in Portuguese).

Ribeiro, R.N.S.; Santana, A.C.; Tourinho, M.M. 2004. Exploratory Socioeconomic Analysis of Agroforestry Systems in Tidal River Floodplains, Cametá, Pará, Brazil. Revista de Economia e Sociologia Rural, Rio de Janeiro, 42: 133-152 (in Portuguese).

Rufino, M.U.L.; Costa, J.T.M.; Silva, V.A.; Andrade, L.H.C. 2008. Knowledge and use of ouricuri (Syagrus coronata) and babaçu (Orbignya phalerata) in Buíque, Pernambuco State, Brazil. Acta Botanica Brasilica, 22: 1141-1149 (in Portuguese).

Seplan- Secretaria executiva de estado de planejamento, orçamento e finanças. 2005. Estatistica Municipal, Abaetetuba-PA.

Sousa, M J.S. 2009. Ethnography of the production of artifacts and crafts in communities of Sustainable Development Reserve Amanã- Médio Solimôes. Uakari, 5:21-37 (in Portuguese).

Valente, R.M. 2002. The palms and communities, p. 165-175. In: Lisboa, P.L.B. (Eds). Caxiuanã: Traditional Populations, Physical Environment and Biological Diversity. Museu Paraense Emílio Goeldi, Belém (in Portuguese).

Vilhena- Potiguara, R.C; Almeida, S.S.; Oliveira, J.; Lobato, L.C.B.; Lins, A.L.F.A. Fibrous Plants-I. Botanical survey in the Salgado microregion (Pará, Brasil). 1987. Boletim do Museu Paraense Emílio Goeldi, Série Botânica, 3: 279-303 (in Portuguese).

Recebido em 02/12/2010

Aceito em 12/02/2011 
